\title{
Chronic Enterovirus D68 Bronchiolitis Causing Severe Respiratory Insufficiency
}

\author{
John Chia ${ }^{1 * \#, ~ A n d r e w ~ C h i a 1, ~ D a v i d ~ W a n g 1, ~ R a b i h a ~ E l-H a b b a l 1, ~ D e r e n ~ S i n k o w i t z ~}{ }^{2 \#}$ \\ ${ }^{1}$ EV Med Research, Torrance, USA \\ ${ }^{2}$ Peninsula Pulmonary Medical Associates, Torrance, USA \\ Email: "evmed@sbcglobal.net
}

Received 15 May 2016; accepted 16 July 2016; published 19 July 2016

Copyright (C) 2016 by authors and Scientific Research Publishing Inc.

This work is licensed under the Creative Commons Attribution International License (CC BY).

http://creativecommons.org/licenses/by/4.0/

(c) (i) Open Access

\begin{abstract}
Human enteroviruses are less well-known causes of acute bronchiolitis. In recent years, Enterovirus D68 [EV D68] has emerged as significant cause of epidemic viral bronchiolitis and pneumonia in the United States and other countries. Chronic bronchiolitis has not been previously attributed to EV D68. We documented EV D68 in open lung biopsies of a young adult patient who was frequently admitted to the hospital for severe exacerbation of respiratory infections and subsequently developed progressive respiratory insufficiency. The difficulty of diagnosis and potential economic impact of this illness is discussed.
\end{abstract}

\section{Keywords}

\section{Enterovirus D68, Chronic Bronchiolitis}

\section{Introduction}

Human enteroviruses are common causes of viral infection [1]. Other than the commonly recognized infections such as summer cold, meningitis, encephalitis, myocarditis, hand-foot-mouth disease and herpangina, enteroviruses, especially EV D68, are known causes of bronchiolitis in infants, children and young adults [2]-[6]. This report demonstrated chronic EV D68 bronchiolitis and focal organizing pneumonia by open lung biopsy in one patient with persistent and progressive lung disease after acute infection.

Case history: 24-year-old Asian female was well until January 2008 when she developed symptoms of chest

\footnotetext{
${ }^{*}$ Corresponding author.

"The two physician authors [J.C., D.S.] contributed to the care of the patient and preparation of the manuscript; others provided the laboratory research.
}

How to cite this paper: Chia, J., Chia, A., Wang, D., El-Habbal, R. and Sinkowitz, D. (2016) Chronic Enterovirus D68 Bronchiolitis Causing Severe Respiratory Insufficiency. Open Journal of Respiratory Diseases, 6, 47-51. 
congestion, mild cough, dyspnea, inspiratory and expiratory rhonchi and wheezes consistent with acute asthmatic bronchitis. After failing outpatient oral steroids and antibiotic therapy, she was hospitalized for IV antibiotics, methylprednisolone $80 \mathrm{mg}$ every 6 hours but the respiratory status worsened requiring intubation and respirator support. Methylprednisolone was withdrawn over the next 2 days, and intravenous immunoglobulin [IVIG] at 0.4 gram $/ \mathrm{Kg}$ per day was administered for 3 days with gradual improvement of her condition. At bronchoscopy, significant white mucus was seen in the major and segmental bronchi. Cultures of bronchoalveolar lavage fluid did not yield any bacteria, acid-fast bacilli, fungi and viruses. HIV antibody was negative and the result of a T lymphocyte enumeration panel was normal. IgG 3 subclass was $6 \mathrm{mg} / \mathrm{dl}$ [normal value 20 110] but subclasses 1, 2, 4 and IgA level were normal. Neutralizing antibody to Coxsackievirus B1-6 and echoviruses 6, 7, 9, 11, 30 were repeatedly negative. Antibody for parainfluenza viruses and adenoviruses were negative.

After the initial 1-month hospitalization, the patient was readmitted every 1 - 2 months for severe exacerbation of her chronic lung disease requiring occasional intubation and ventilator support. She developed progressive weakness since the first admission followed by paralysis of left lower extremity, which did not improve with physical therapy. Tracheostomy was performed 3 years later for secretion control. Different gram-positive and gram-negative bacterial tracheobronchitis, starting in the $2^{\text {nd }}$ year of illness, were treated with prolonged courses of antibiotics. Repeated chest x-ray and high-resolution CT scan of chest showed no significant findings. Pulmonary function test [PFT] showed decreased FEV1, FVC and $\mathrm{FEF}_{25 \%-75 \%}$.

A transbronchial biopsy done in the first year of illness demonstrated normal cilia function; and comprehensive viral cultures of repeated bronchial washing and bronchoalveolar lavage showed negative results. Sweat tests and genetic screening for cystic fibrosis were unremarkable.

In $2 / 2010$, 2 years after onset of symptoms, open lung biopsy of the right upper and lower lobes were performed after hospitalization for severe exacerbation of lung disease. White mucus exuded from the edge of the lung biopsies with digital pressure. Cultures for bacteria, acid fast bacilli, fungi were negative.

The lung tissue was cultured in WI-38 embryonic lung fibroblasts and enterovirus RNA was quantitated after 72 hours of incubation, as described [7]. Positive RNA samples were amplified with non-biotinylated primers and cloned into P-drive vector as described [6], and sequenced by Retrogen [San Diego, Ca]. Amplification and sequencing of viral capsid protein 1 gene was performed as described by Nix and Oberste [8]. The cDNA product was directly sequenced with AN89 primer [8].

No significant response was seen with repeated courses of IVIG, interferon- $\alpha$ 2a or interferon- $\beta$ injections. She continued to have diffuse, audible rhonchi with significant mucus production. The patient had progressive hypoxemia requiring $35 \%-40 \% \mathrm{FiO}_{2}$ in 2010 . For the last 5 years, the patient was wheelchair-bound and supported with a portable ventilator. The charges and actual payments for hospitalizations over first 4 years exceeded \$ 4 and \$ 1.5 million, respectively.

\section{Results}

Microscopic examination of the lung tissues showed extensive chronic inflammation around bronchioles with focal organizing pneumonia. Mucus plugging was demonstrated (Figure 1). Special stains for acid fast bacilli, fungi, and bacteria are negative, and no parasites are identified.

$50 \%$ of WI 38 cells infected with RUL samples showed cytopathic effect in 3 days, whereas cells infected with RLL lobe samples showed minimal cell lysis, as compared to the negative control wells. Significant enterovirus RNA was detected in the cell cultures on day 3 but then started to decline over next few days (Table 1). Lysates co-cultured with WI-38 cells for 72 hours yielded much higher level of enterovirus RNA, as compared to wells incubated with lysates for only 12 hours. EV D68 VP1 gene sequence was confirmed by direct sequencing.

\section{Discussion}

This is the first case of pathologically-proven chronic EV D68 bronchiolitis in patient initially presented with acute "asthmatic bronchitis" followed by frequent exacerbations and progressive lung dysfunction over next few years. Although she had audible rhonchi and significant mucus production from the onset and continued until the present, pulmonary function tests were fairly normal except for decrease $\mathrm{FEF}_{25 \%-75 \%}$, consistent with small airway disease. Without an open lung biopsy, the diagnosis eluded clinicians for 2 years. 

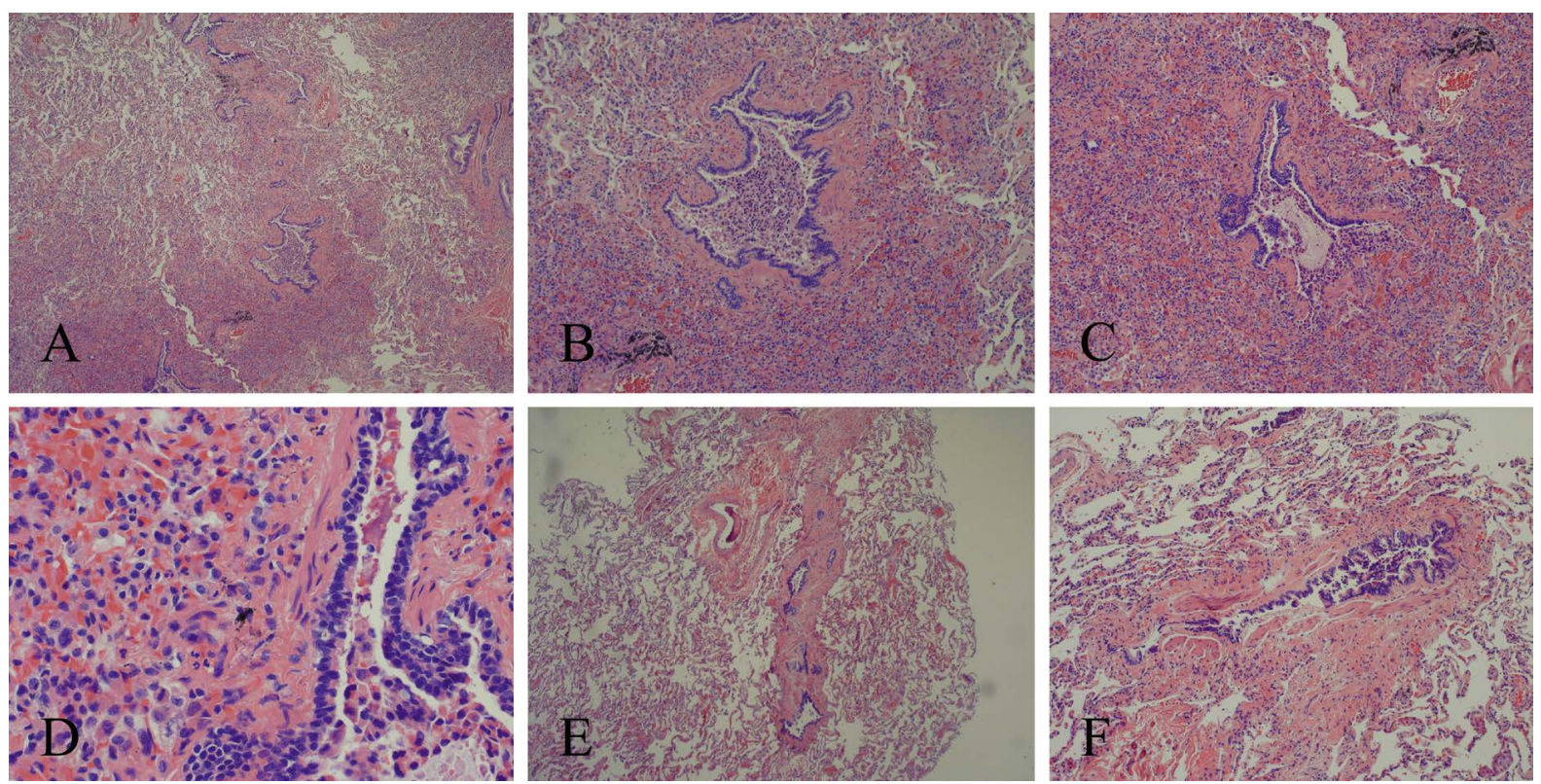

Figure 1. H \& E staining of one piece of right upper lobe biopsy demonstrated severe extensive chronic bronchiolitis and focal organizing pneumonia with mucus plugging: panel A, 40× magnification; panel B,C represented 100× magnification of two areas of A showing severe chronic inflammation and mucus plugging of the brochioles; panel D, 400× magnification of the involved area. Panels E, F represented another piece of the upper lobe biopsy with less severe involvement [40 $\times$ and $100 \times$ magnification, respectively].

Table 1. Culture of lung tissue lysates in WI-38 human embryonic fibroblasts for enterovirus.

\begin{tabular}{ccccc}
\hline Location of Biopsy & Co-incubation with lysates ${ }^{*}$ & & EV RNA [copies] $^{* *}$ & \\
\hline & & Day 3 & Day 8 & Day 28 \\
\hline R upper lobe & $12 \mathrm{~h}$ & 12,000 & 323 & $<50$ \\
R upper lobe & $72 \mathrm{~h}$ & 32,300 & 3660 & $<50$ \\
R lower lobe & $12 \mathrm{~h}$ & $<50$ & 320 & $<50$ \\
R lower lobe & $72 \mathrm{~h}$ & $<50$ & $<50$ & nd \\
Neg. control & $12 \mathrm{~h}$ & $<50$ & $<50$ & nd \\
Neg. control & $72 \mathrm{~h}$ & $<50$ &
\end{tabular}

${ }^{*}$ The lung lysate was incubated with WI-38 cell monolayer for 12 or 72 hours before the lysate was removed. ${ }^{* *}$ One quadrant of the infected cell monolayer was scraped on days 3, 8 and 28 after removing most of the media, and $250 \mathrm{ul}$ of cell suspensions were processed analyzed for EV RNA as described. The copies of viral RNA found in the infected cells were calculated based on a cDNA standard ran simultaneously. The amplified cDNA was confirmed as enterovirus sequence.

Enteroviruses were not detected in the initial bronchial secretions 2 months into her initial illness despite prolonged course of corticosteroids. Previous study showed that rhinovirus can persist in the nasal secretion for 5 6 weeks after children developed acute respiratory infection with expiratory wheezing, but EV RNA usually disappears after 2 - 3 weeks [5]. Except in the cases of transplant-recipients, respiratory or stool specimens were rarely positive in our hospitalized adult patients with suspected acute enteroviral infections, even in cases proven by sero-conversion. Similar to chronic enterovirus infection of the stomach [7], the diagnosis of chronic lung infection may be difficult without special staining for viral protein or cultures of lung tissues. The sensitivity of transbronchial biopsies is likely inferior to open lung biopsy due to smaller sample size. Although EV D68 could be an incidental finding, the chronic persistent symptoms of bronchitis/bronchiolitis since the onset of illness, the severe chronic inflammatory changes in the lung biopsies, and the finding of this virus provided a reasonable explanation of her illness. 
Chronic enterovirus infection is known to occur in patients with agammaglobulinemia but controversial in immunocompetent hosts [9]. This patient has low IgG3 level, one of the two principle IgG subclasses responsible for neutralizing enteroviruses [10], which likely predispose to more severe infection.

Previously, we demonstrated viral persistence or chronic enteroviral infection in stomach biopsies taken from patients with myalgic encephalomyelitis/chronic fatigue syndrome, and documented chronic diseases with viral persistence in the stomach following acute infection [5]. Our laboratory demonstrated persistent, non-cytopathic EV D68 infection in Hela cells beyond 2 months (author's unpublished observation).

This patient also developed progressive areflexic paralysis of the left lower extremity since onset of illness. MRI scan of brain and spinal cord performed one year later did not demonstrate significant abnormalities. Recently, large cluster of cases of acute flaccid myelitis associated with EV D68 infection were reported in United States, many of them had abnormalities of the spinal cord in the beginning of the illness [11].

EV-D68 was first isolated from 4 pediatric patients with bronchiolitis and severe pneumonia in California in 1962. While most of the 100 genotypes of enteroviruses primarily infect the gastrointestinal tract, EV-D68 has tropism for the respiratory tract causing acute respiratory disease ranging from mild upper respiratory tract symptoms to severe pneumonia. In an outpatient setting, EV-D68 disease has manifested most commonly among persons younger than 20 years and adults aged 50 - 59 years. Inpatients have predominately been children, and susceptible patients generally have underlying asthma and wheezing. In August 2014, EV-D68 emerged as a major cause of severe respiratory infections across the entire United States [12]-[14]. There is no published report on chronic EV D68 pulmonary disease in these patients.

The cost of medical care for this single patient with chronic EV D68 infection of the lungs was enormous, but the prevalence of chronic viral bronchitis/bronchiolitis following countless cases of acute respiratory tract infection can never be defined without clear virologic diagnosis of the acute infection at the onset of illness and meticulous follow-up. Similar to this case, other patients were frequently readmitted to hospitals for acute exacerbations of chronic inflammatory lung disease/chronic obstructive pulmonary disease, and continued to receive intravenous steroids, the mainstay of therapy for asthma/bronchial inflammation, which would block reactive inflammatory responses but may have perpetuated the underlying virus infection. The risk and benefits and the timing of steroids treatment in patients with acute viral tracheobronchitis/bronchiolitis needs to be individualized. If chronic lung diseases develop in a significant number of patients following acute enterovirus infection documented by rapid molecular diagnostic test and appropriate genotyping [15], the need for antiviral drug will become readily apparent.

Recently, a number of compounds were found to have broad-spectrum inhibitory activities against enteroviruses, including enterovirus D68. Hopefully, antiviral treatment will change the natural history of this disease [16] [17].

\section{Acknowledgements}

We want to thank the number of hospitalists who have taken excellent care of this patient during multiple hospitalizations.

\section{Funding}

Funding is provided from EV Med Research LLC.

\section{Competing Interest}

None to declare.

\section{Consent}

Written informed consent was obtained from the patient to report this case.

\section{References}

[1] Oberste, M.S. and Pallansch, M. (2003) Establishing Evidence for Enterovirus Infection in Chronic Diseases. Annals of the New York Academy of Sciences, 1005, 23-31. http://dx.doi.org/10.1196/annals.1288.004 
[2] Jacques, J., Bouscambert-Duchamp, M., Moret, H., Carquin, J., Brodard, V., Lina, B., Motte, J. and Andréoletti, L. (2006) Association of Respiratory Picornaviruses with Acute Bronchiolitis in French Infants. Journal of Clinical Virology, 35, 463-466. http://dx.doi.org/10.1016/j.jcv.2005.11.009

[3] Imamura, T., Fuji, N., Suzuki, A., et al. (2011) Enterovirus 68 among Children with Severe Acute Respiratory Infection, Philippines. Emerging Infectious Diseases, 17, 1430-1435. http://dx.doi.org/10.3201/eid1708.101328

[4] Centers for Disease Control and Prevention (2011) Clusters of Acute Respiratory Illness Associated with Human Enterovirus 68-Asia, Europe, and United States, 2008-2010. Morbidity and Mortality Weekly Report (MMWR), 60(38): 1301-1304.

[5] Jartti, T., Lehtinen, P., Vuorinen, T., Koskenvuo, M. and Ruuskanen, O. (2004) Persistence of Rhinovirus and Enterovirus RNA after Acute Respiratory Illness in Children. Journal of Medical Virology, 72, 695-699. http://dx.doi.org/10.1002/jmv.20027

[6] Andréoletti, L., Lesay, M., Deschildre, A., Lambert, V., Dewilde, A. and Wattré, P. (2000) Differential Detection of Rhinoviruses and Enteroviruses RNA Sequences Associated with Classical Immunofluorescence Assay Detection of Respiratory Virus Antigens in Nasopharyngeal Swabs from Infants with Bronchiolitis. Journal of Medical Virology, 61, 341-346. http://dx.doi.org/10.1002/1096-9071(200007)61:3<341::AID-JMV10>3.0.CO;2-0

[7] Chia, J. and Chia, A. (2008) Chronic Fatigue Syndrome Is Associated with Chronic Enterovirus Infection of the Stomach. Journal of Clinical Pathology, 61, 43-48. http://dx.doi.org/10.1136/jcp.2007.050054

[8] Nix, W.A., Oberste, S. and Pallansch, M. (2006) Sensitive, Semi-Nested PCR Amplification of VP1 Sequences for Direct Identification of Enterovirus Serotypes from Clinical Specimens. Journal of Clinical Microbiology, 44, $2698-2704$. http://dx.doi.org/10.1128/JCM.00542-06

[9] O’Neil, K.M., Pallansch, M.A., Winkelstein, J.A., et al. (1988) Chronic Group A Coxsackievirus Infection in Agammaglobulinemia: Demonstration of Genomic Variation of Serotypically Identical Isolates Persistently Excreted from the Same Patient. The Journal of Infectious Diseases, 157, 183-186. http://dx.doi.org/10.1093/infdis/157.1.183

[10] Torfason, E.G. and Reimer, C. (1987) Keyserling Subclass Restriction of Human Enterovirus Antibodies. Journal of Clinical Microbiology, 25, 1376-1379.

[11] Lesham, E. (2015) Acute Flaccid Myelitis among Persons Age <21 Years-United States, August 1-November 13, 2014. Morbidity and Mortality Weekly Report (MMWR), 63, 1143-1244.

[12] Meijer, A., Benschop, K.S., Donker, G.A. and van der Avoort, H.G. (2014) Continued Seasonal Circulation of Enterovirus D68 in the Netherlands, 2011-2014. Eurosurveillance, 19, pii=20935. http://dx.doi.org/10.2807/1560-7917.es2014.19.42.20935

[13] Midgley, C.M., Jackson, M.A., Selvarangan, R., Turabelidze, G., Obringer, E., Johnson, D., et al. (2014) Severe Respiratory Illness Associated with Enterovirus D68-Missouri and Illinois, 2014. Morbidity and Mortality Weekly Report (MMWR), 63, 798-799.

[14] Imamura, T. and Oshitani, H. (2015) Global Reemergence of Enterovirus D68 as an Important Pathogen for Acute Respiratory Infections. Reviews in Medical Virology, 25, 102-114. http://dx.doi.org/10.1002/rmv.1820

[15] Merante, F., Yaghoubian, S., Janeczko, R., et al. (2007) Principles of the xTag Respiratory Viral Panel Assay [RVP Assay]. Journal of Clinical Virology, 40, S31-S35. http://dx.doi.org/10.1016/S1386-6532(07)70007-0

[16] Sun, L., Meijer, A., Froeyen, M., et al. (2015) Antiviral Activity of Broad-Spectrum and Enterovirus-Specific Inhibitors against Clinical Isolates of Enterovirus D68. Antimicrobial Agents and Chemotherapy, 59, 7782-7785. http://dx.doi.org/10.1128/AAC.01375-15

[17] Zuo, J., Kye, S., Quinn, K., Cooper, P., Damoiseauux, R. and Krogstad, P. (2016) Discovery of Structurally Diverse Small-Molecule Compounds with Broad Antiviral Activities against Enteroviruses. Antimicrobial Agents and Chemotherapy, 60, 1615-1626. http://dx.doi.org/10.1128/AAC.02646-15 


\section{Submit or recommend next manuscript to SCIRP and we will provide best service for you:}

Accepting pre-submission inquiries through Email, Facebook, LinkedIn, Twitter, etc.

A wide selection of journals (inclusive of 9 subjects, more than 200 journals)

Providing 24-hour high-quality service

User-friendly online submission system

Fair and swift peer-review system

Efficient typesetting and proofreading procedure

Display of the result of downloads and visits, as well as the number of cited articles

Maximum dissemination of your research work

Submit your manuscript at: http://papersubmission.scirp.org/ 